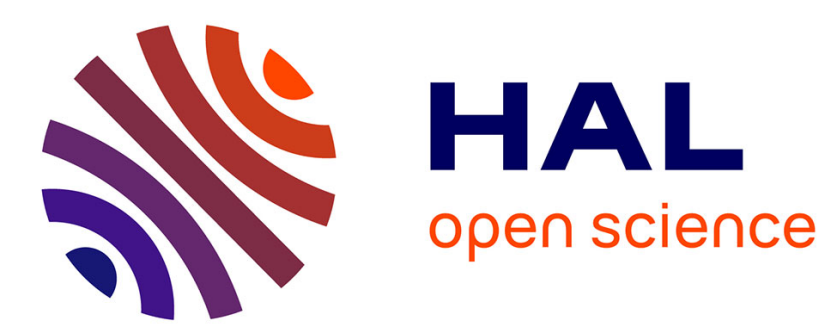

\title{
Data Communication in VANETs: Survey, Applications and Challenges
}

Felipe Domingos da Cunha, Leandro Villas, Azzedine Boukerche, Guilherme Maia, Aline Carneiro Viana, Raquel A. F. Mini, Antonio A. F. Loureiro

\section{- To cite this version:}

Felipe Domingos da Cunha, Leandro Villas, Azzedine Boukerche, Guilherme Maia, Aline Carneiro Viana, et al.. Data Communication in VANETs: Survey, Applications and Challenges. Ad Hoc Networks, 2016, 44 (C), pp.90-103. 10.1016/j.adhoc.2016.02.017 . hal-01369972

\section{HAL Id: hal-01369972 https://hal.science/hal-01369972}

Submitted on 23 Sep 2016

HAL is a multi-disciplinary open access archive for the deposit and dissemination of scientific research documents, whether they are published or not. The documents may come from teaching and research institutions in France or abroad, or from public or private research centers.
L'archive ouverte pluridisciplinaire HAL, est destinée au dépôt et à la diffusion de documents scientifiques de niveau recherche, publiés ou non, émanant des établissements d'enseignement et de recherche français ou étrangers, des laboratoires publics ou privés. 


\title{
Data Communication in VANETs: Survey, Applications and Challenges
}

\author{
Felipe Cunha ${ }^{\mathrm{a}, \mathrm{b}, *}$, Leandro Villas ${ }^{\mathrm{c}}$, Azzedine Boukerche ${ }^{\mathrm{d}}$, Guilherme Maia ${ }^{\mathrm{a}}$, \\ Aline Viana ${ }^{\mathrm{b}}$, Raquel A. F. Mini ${ }^{\mathrm{e}}$, Antonio A. F. Loureiro ${ }^{\mathrm{a}}$ \\ ${ }^{a}$ Federal University of Minas Gerais, Brazil \\ ${ }^{b}$ INRIA, Saclay, France \\ ${ }^{c}$ Institute of Computing, University of Campinas, Brazil \\ ${ }^{d}$ SITE, University of Ottawa, Canada \\ ${ }^{e}$ Pontifical Catholic University of Minas Gerais, Brazil
}

\begin{abstract}
VANETs have emerged as an exciting research and application area. Increasingly vehicles are being equipped with embedded sensors, processing and wireless communication capabilities. This has opened a myriad of possibilities for powerful and potential life-changing applications on safety, efficiency, comfort, public collaboration and participation, while they are on the road. Although, considered as a special case of a Mobile Ad Hoc Network, the high but constrained mobility of vehicles bring new challenges to data communication and application design in VANETs. This is due to their highly dynamic and intermittent connected topology and different application's QoS requirements. In this work, we survey VANETs focusing on their communication and application challenges. In particular, we discuss the protocol stack of this type of network, and provide a qualitative comparison between most common protocols in the literature. We then present a detailed discussion of different categories of VANET applications. Finally, we discuss open research problems to encourage the design of new VANET solutions.
\end{abstract}

Keywords: Vehicular Networks, Ad Hoc Networks, Survey.

${ }^{*}$ Corresponding author. Tel.: +55 31 34095863. Fax.: +55 3134095858

Email addresses: fdcunha@dcc.ufmg.br (Felipe Cunha), leandro@ic.unicamp.br (Leandro Villas), boukerch@site.uottawa.com (Azzedine Boukerche), jgmm@dcc.ufmg.br (Guilherme Maia), aline.viana@inria.fr (Aline Viana), raquelmini@pucminas.br (Raquel A. F. Mini), loureiro@dcc.ufmg.br (Antonio A. F. Loureiro) 


\section{Introduction}

Information and communication technology are the driving force behind some of the most important innovations in the automotive industry and in our society. In the last two decades, mobile communications have changed our lifestyles allowing us to exchange information, anywhere at any time. The use of such mobile communications systems in vehicles is expected to be a reality in the next years. This new paradigm of sharing information among vehicles and infrastructure will enable a variety of applications for safety, traffic efficiency, driver assistance, infotainment, and urban sensing, to be incorporated into modern vehicle designs. These applications will be a reality once emerging vehicular networks in the forms of intra-vehicle, vehicle-tovehicle and vehicle-to-infrastructure communications are widely available. This is expected to be the case since industry, telecom and network operators, academia, and governments worldwide are devoting expressive resources on the deployment of vehicular networks to have a more secure transportation infrastructure. This can be certified by different national and international projects in government, industry, and academia devoted to vehicular networks [51].

Given the advances in information technology and communication, the concept of a networked vehicle has received immense attention all over the world. A current trend is to provide vehicles and roads with capabilities to make the transportation infrastructure more secure, more efficient, urban aware, and to make passengers' time on the road more enjoyable. In this context, a more secure transportation infrastructure means to provide information about traffic jams, accidents, hazardous road conditions, possible detours, weather conditions, and location of facilities (e.g., gas stations and restaurants) [11]; more efficient means an increased road network capacity, reduced congestion and pollution [9], shorter and more predictable journey times, lower vehicle operating costs, more efficient logistics, improved management and control of the road network, and increased efficiency of the public transport systems [69]. Vehicles can also be used to collect, analyze and share knowledge of an Area of Interest (AoI) [75] in applications such as civilian surveillance (photo shots of violence scenes in progress sent to public authorities via infrastructure), pollution control, roads and traffic planning and innumerable others urban-aware applications. Finally, more enjoyable means to provide Internet access, tourist/advertising information, social media on the road, guidance for people to follow each other on the road, games, file downloads, and social applications (e.g., microblogs and chats) [4]. These applications are typical examples of what we call an Intelligent Transportation System (ITS), whose goal is to improve safety, efficiency, urban awareness and enjoyment in transportation systems through the use of new technologies for information and communication. 
An important component of an ITS is the vehicular communication network (VANET) that enables information exchange among vehicles. A VANET is a special case of a Mobile Ad Hoc Network (MANET) in which vehicles equipped with wireless and processing capabilities can create a spontaneous network while moving along roads. Direct wireless communication from vehicle to vehicle make it possible to exchange data even where there is no communication infrastructure, such as base stations of cellular phones or access points of wireless networks.

A VANET will be a major step toward the realization of intelligent transportation systems. Nowadays, a large number of car manufacturers are supplying vehicles with onboard computing and wireless communication devices, in-car sensors, and navigation systems (e.g., GPS and Galileo) in preparation for the deployment of large-scale vehicular networks. By using different sensors (e.g., road and weather conditions, state of the vehicle, radar and others), cameras, computing and communication capabilities, vehicles can collect and interpret information with the purpose of helping the driver to make a decision, particularly in driver assistance systems. In this case, there is a strong support from the industry, academia, and standardization agencies to develop standards and prototypes for vehicular networks.

In the literature, there are several studies addressing different aspects of a VANET, such as: applications [68, 70], communication [10, 29, 42, 62, 73], security [57], routing protocols [15, 37, 52, 58], cloud computing in VANETs [72], and general aspects [1]. We claim that a study more focused on the protocol stack and application requirements is lacking in the literature. Therefore, this survey provides an in-depth discussion on these issues, including a detailed qualitative comparison of protocols from different layers. It also presents a comprehensive overview of the current state of the art of applications and data communication in VANETs. In addition, some challenges and future perspectives for vehicular networks are discussed in order to guide new researches.

This work is organized as follows. Section 2 presents more characteristics of VANETs. Section 3 presents the protocol stack for VANETs. Section 4 discusses existing and future applications for vehicular networks. Section 5 debates some communication challenges for VANETs. Finally, Section 6 concludes this work and presents some future directions.

\section{VANET Background}

The advances in mobile communications and the current trends in ad hoc networks allow different deployment architectures for vehicular networks in highways, urban and rural environments to support many applications with different QoS requirements. 
The goal of a VANET architecture is to allow the communication among nearby vehicles and between vehicles and fixed roadside equipments leading to the following three possibilities (as shown in Figure 1):

- Vehicle-to-Vehicle (V2V) ad hoc network: allows the direct vehicular communication without relying on a fixed infrastructure support and can be mainly employed for safety, security, and dissemination applications;

- Vehicle-to-Infrastructure (V2I) network: allows a vehicle to communicate with the roadside infrastructure mainly for information and data gathering applications;

- Hybrid architecture: combines both Vehicle-to-Vehicle (V2V) and Vehicle-toInfrastructure (V2I). In this scenario, a vehicle can communicate with the roadside infrastructure either in a single hop or multi-hop fashion, depending on the distance, i.e., if it can or not access directly the roadside unit. It enables long distance connection to the Internet or to vehicles that are far away.

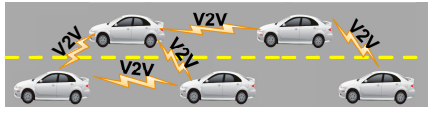

(a) Vehicle-to-Vehicle Ad Hoc (b) Network

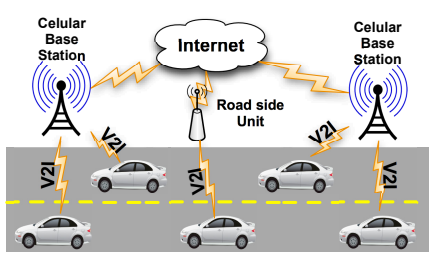

Network

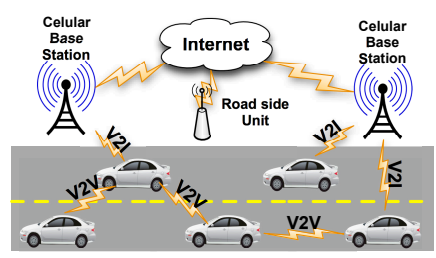

(c) Hybrid Architecture

Figure 1: VANET Architectures

A VANET has some particular features despite being a special case of a MANET and presenting some similar characteristics, such as low bandwidth, short transmission range and omnidirectional broadcast:

- Highly dynamic topology: a vehicular network is highly dynamic due to two reasons: speed of the vehicles and characteristics of radio propagation. Vehicles have high relative velocities in the order of $50 \mathrm{~km} / \mathrm{h}$ in urban environments to more than $100 \mathrm{~km} / \mathrm{h}$ in highways. They may also move at different directions. Thus, vehicles can quickly join or leave the network in a very short period of time, leading to frequent and fast topology changes. 
- Frequently disconnected: the highly dynamic topology results in frequent changes in its connectivity, thus the link between two vehicles can quickly disappear while they are transmitting information;

- Geographical communication: vehicles to be reached typically depend on their geographical location. This differs from other networks where the target vehicle or a group of target vehicles are defined by an ID or a group ID;

- Constrained mobility and prediction: VANETs present highly dynamic topology, but vehicles usually follow a certain mobility pattern constrained by roads, streets and highways, traffic lights, speed limit, traffic conditions, and drivers' driving behaviors. Thus, given the mobility pattern, the future position of the vehicle is more feasible to be predicted;

- Propagation model: typically, VANETs operate in three environments: highway, rural, and city. In a highway, the propagation model is usually assumed to be free-space, but the signal can suffer interference by the reflection with the wall panels around the roads. In a city, its surroundings make the communication complex due to the variable vehicle density and the presence of buildings, trees, and other objects, acting as obstacles to the signal propagation. Such obstacles cause shadowing, multi-path, and fading effects. Usually, the propagation model is assumed to not be free-space due to those characteristics of the communication environment. In rural environments, due to the complex topographic forms (fields, hills, climbs, dense forests, etc.), it is important to consider the signal reflection and the attenuation of the signal propagation. Therefore, in this scenario, the free-space model is not appropriate. As in any other network, the propagation model in a VANET must consider the effects of potential interference of wireless communication from other vehicles and the existence of largely deployed access points.

All these features bring new challenges to the design of communication protocols in VANETs. The spatial-temporal constraints of this type of network and the heterogeneity of vehicles in terms of speed and mobility are design factors to be considered in the development of algorithms and protocols for vehicle networks. For instance, taking into account cars and trucks versus buses and trams: cars and trucks have different speeds and tend to follow an unpredictable mobility model, whereas buses and trams have a regular, slower speed and a predictable mobility model. 


\section{Protocol Stack for VANETs}

The protocol stack for vehicular networks has to deal with communication among nearby vehicles, and between vehicles and fixed roadside equipment considering their distinct characteristics. Since there is no coordination or prior configuration to set up of a VANET, there are several challenges in the protocol design. In the following sections, we discuss protocols for VANETs according to each layer of the network architecture.

\subsection{Physical layer}

Protocols for the physical layer have to consider multipath fading and Doppler frequency shifts caused by fast movements of nodes among roadway environment. Experimental vehicle-to-vehicle communications have used radio and infrared waves [54]. Very high frequency, micro, and millimeter waves are examples of radio waves used for V2V communications. Both infrared and millimeter waves are suitable only for line-of-sight communications, whereas VHF and microwaves provide broadcast communications. In particular, VHF supports long-range links at low speeds and, because of that, the trend is to use microwaves.

Defined specifically to VANETs, the DSRC (Dedicated Short-Range Communication) system is a short to medium range communication technology that operates in the $5.9 \mathrm{GHz}$ band for the use of public safety and private applications [31]. Therefore, in the United States, the Federal Communications Commission (FCC) allocated $75 \mathrm{MHz}$ in the 5.850-5.925 GHz band for DSRC, in contrast to the European Telecommunications Standards Institute (ETSI), which allocated $70 \mathrm{MHz}$ in the $5.855-5.925 \mathrm{GHz}$ band. The DSRC system supports a vehicle speed up to $200 \mathrm{~km} / \mathrm{h}$, nominal transmission range of $300 \mathrm{~m}$ (up to $1000 \mathrm{~m}$ ), and the default data rate of $6 \mathrm{Mbps}$ (up to $27 \mathrm{Mbps})$.

DSRC is known as IEEE 802.11p WAVE (Wireless Access in Vehicular Environments), designed based on earlier standards for Wireless LANs [27]. It describes function and services that coordinate the operation in a rapidly varying environment and exchange the message without having to join a Basic Service Set (BSS). IEEE 802.11p also defines techniques and interface functions that are controlled by the MAC layer. Therefore, it is limited by the scope of the IEEE 802.11 standard, which means that the physical and MAC layers work within a single logical channel. As we can see in the Figure 2, the other complexities related to the DSRC channel are treated by the upper layer, according to the IEEE 1609 standards.

As we can see in Figure 3, the frequency band is divided into six service channels $(\mathrm{SCH})$ and one control channel $(\mathrm{CCH})$ with equal bandwidth of $10 \mathrm{MHz}$ each one. 


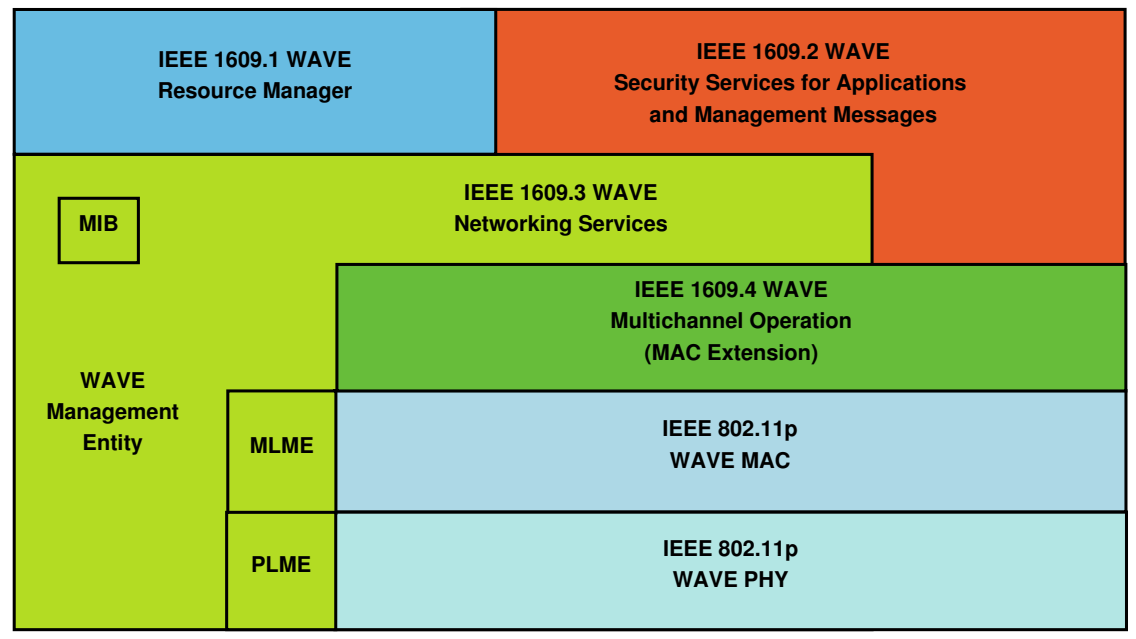

Figure 2: The IEEE 1609 (WAVE) reference architecture and relationship to the IEEE 802.11p MAC and physical layers [19].

According to the ETSI Institute [22], each channel is attributed for a application type: from the range $5.855 \mathrm{MHz}$ to $5.875 \mathrm{MHz}$ is dedicated to ITS non-safety applications, $5.875 \mathrm{MHz}$ to $5.905 \mathrm{Mhz}$ is dedicated to safety and traffic efficiency applications, and $5.905 \mathrm{MHz}$ to $5.925 \mathrm{Mhz}$ to future applications in ITS. In DSRC, the entire spectrum is divided into time slots of $50 \mathrm{~ms}$ and messages have two different priorities: low for data dissemination messages transmitted in the SCH channels, or high for safety or control messages transmitted in the $\mathrm{CCH}$ channel. All vehicles monitor these messages. If the $\mathrm{CCH}$ channel is active, all nodes are bound to stop their communication during the $\mathrm{CCH}$ time frame to receive and transmit security messages in the $\mathrm{CCH}$ channel. DSRC is proposed to support communication between vehicles and roadside units. 


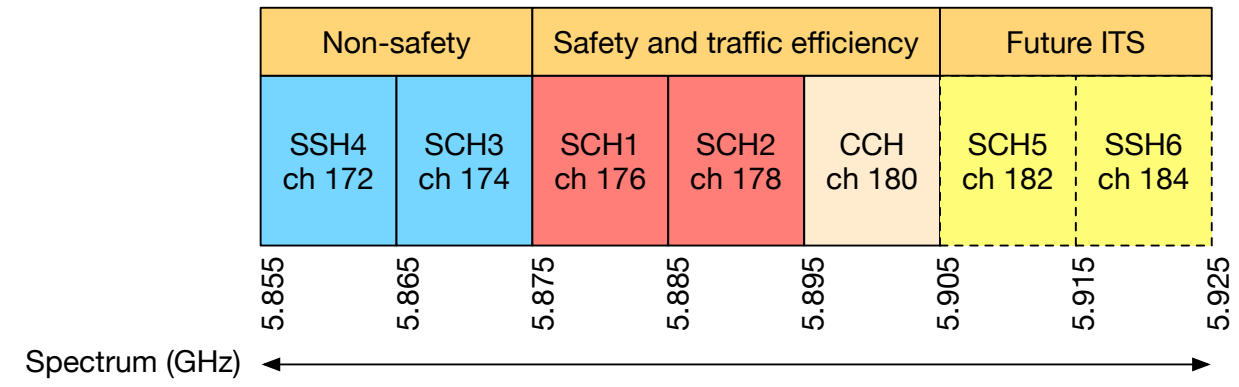

Figure 3: Multichannel operation in vehicular networks according to the IEEE 802.11p European standard [14].

Within the IEEE 802.11 technical committee, the IEEE 802.11p WAVE protocol proposes amendments to the physical (PHY) and medium access control (MAC) layers of the existing IEEE 802.11 wireless standards to support ITS applications. This includes data exchanges among high-speed vehicles and between vehicles and the roadside infrastructure in the $5.9 \mathrm{GHz}$ band. The ultimate goal is to have WAVE as an international standard applicable worldwide.

\subsection{MAC layer}

The MAC layer has to provide a reliable, fair and efficient channel access. MAC protocols should consider the different kinds of applications for which the transmission will occur. For instance, messages related to safety applications must be sent quickly and with very low failure rates. This calls for an efficient medium sharing, which is even more difficult in VANETs due to high node mobility and fast topology changes.

MAC protocols for VANETs [2] have to deal with the hidden station problem, which frequently shows up in scenarios where vehicles form long rows causing a decrease on the data transfer. This is especially important since there is a trend to make available multimedia applications for passengers in vehicular networks that will demand a higher data rate. Furthermore, in VANET, the bandwidth has to be shared among the communicating vehicles. In the following, we briefly discuss about the MAC protocols for VANETs found in literature, clustering the protocols according to the medium access control mechanism.

Making use of OFDM technology to control the medium access and carrier sense mechanism to avoid collisions, the protocol IEEE 802.11p WAVE is designed to fulfill the requirements present in V2V and V2I communications patterns, where high reliability and low latency are extremely important requirements. The key is to enable a very efficient communication group setup without much of the overhead, simplifying the BSS operations from IEEE 802.11 in a truly ad hoc manner for vehicle usage. For 
example, in the United States the Vehicle Infrastructure Integration (VII) initiative proposed that information about an accident should be communicated through a VANET within $500 \mathrm{~ms}$ to all equipped vehicles in a $500 \mathrm{~m}$ range [46].

Similar to the IEEE 802.11 standard, the Directional MAC (D-MAC) [32] protocol proposes two different schemes: an ACK is sent immediately after a DATA, and if a given terminal is aware of an ongoing transmission between some other two terminals, the former does not participate in a transfer itself. D-MAC scheme 1 uses directional RTS frames, and D-MAC scheme 2 uses both directional RTS and omnidirectional RTS frames. The basic principle of D-MAC is that in case a directional antenna at some terminal is blocked, other directional antennas at the same terminal may not be blocked, allowing transmission using those unblocked antennas. The focus of this protocol is to reduce the collisions and to increase the channel transmission reuse.

In a different way, some MAC protocols use of ALOHA approach to define the transmission schedule. ADHOC MAC [6] uses the Reliable Reservation ALOHA (RR-ALOHA) protocol, a distributed reservation protocol that creates a reliable single-hop broadcast channel, the Basic Channel (BCH). Each BCH carries signaling information to solve both the hidden and exposed terminal problems, and to provide an efficient implementation of a network broadcast service. The basic idea is to have each terminal periodically transmitting the frame information (FI), i.e., the status of slots in the previous period. ADHOC MAC works independently from the physical layer and its main disadvantage is that the medium is not used efficiently. The number of vehicles that can communicate in a given region is not greater than the number of the time slots in the frame time.

In addition, the VC-MAC (Vehicular Cooperative Media Access Control) [77] protocol uses the concept of cooperative communication tailored for VANETs. In order to maximize the system throughput, the broadcast is made by the access point based on the premise that under the information-downloading scenario, all vehicles are interested in the same information. During the transmission, due to the unreliability of the wireless channel, a group of vehicles may not receive the right information. Then, the vehicles that received the information will be selected to relay to their neighbors. Therefore, to reduce the probability of having collisions and interference, the protocol uses only a part of the vehicles to create a group of good relays. The goal of these protocol is to reach good performance good performance in broadcast scenarios, which does not consider others communication scenarios.

Considering the different types of control channels, Shao et al. [61] present the MP-MAC protocol, which uses a technique, which defines different priorities to transmit a packet, starting with safety packets and then control packets. It uses a multi-priority Markov process to optimize the use of the channel according to the 


\begin{tabular}{|c|c|c|c|c|}
\hline Protocol & Main Feature & $\begin{array}{l}\text { Medium } \\
\text { Access }\end{array}$ & Advantage & Drawbacks \\
\hline IEEE 802.11p & $\begin{array}{l}\text { A draft amend- } \\
\text { ment to the } \\
\text { IEEE } 802.11 \\
\text { standard. }\end{array}$ & CSMA/CA & $\begin{array}{l}\text { Design provides re- } \\
\text { liability and low } \\
\text { latency require- } \\
\text { ments. }\end{array}$ & $\begin{array}{l}\text { Lacks QoS and is } \\
\text { not suitable for } \\
\text { real-time traffic. }\end{array}$ \\
\hline DMAC & $\begin{array}{l}\text { Uses directional } \\
\text { antennas. }\end{array}$ & CSMA based. & $\begin{array}{l}\text { Improves the per- } \\
\text { formance and re- } \\
\text { duces collisions. }\end{array}$ & $\begin{array}{l}\text { Assumes that each } \\
\text { terminal is aware of } \\
\text { the geographic po- } \\
\text { sition. }\end{array}$ \\
\hline ADHOC MAC & $\begin{array}{l}\text { Guarantees a } \\
\text { good QoS. }\end{array}$ & RR-ALOHA & $\begin{array}{l}\text { Overcomes the hid- } \\
\text { den terminal prob- } \\
\text { lem and reduces } \\
\text { transmission colli- } \\
\text { sions. }\end{array}$ & $\begin{array}{l}\text { Number of slots is } \\
\text { fixed. }\end{array}$ \\
\hline VC-MAC & $\begin{array}{l}\text { Takes advan- } \\
\text { tage of spatial } \\
\text { reusability un- } \\
\text { der broadcast } \\
\text { scenarios. }\end{array}$ & $\begin{array}{l}\text { Cooperative- } \\
\text { ALOHA }\end{array}$ & $\begin{array}{l}\text { Increases the sys- } \\
\text { tem throughput of } \\
\text { the network and } \\
\text { reduces the colli- } \\
\text { sions. }\end{array}$ & $\begin{array}{l}\text { Design only to lead } \\
\text { with broadcast sce- } \\
\text { nario. }\end{array}$ \\
\hline MP-MAC & $\begin{array}{l}\text { Prioritizes safety } \\
\text { packets and then } \\
\text { control packets. }\end{array}$ & $\begin{array}{l}\text { p-persistent } \\
\text { MAC scheme }\end{array}$ & $\begin{array}{l}\text { Reliable } \\
\text { mission of safety } \\
\text { packets and re- } \\
\text { duces channel } \\
\text { collision. }\end{array}$ & $\begin{array}{l}\text { It is not suitable } \\
\text { for multi-hop com- } \\
\text { munication. }\end{array}$ \\
\hline
\end{tabular}

Table 1: Comparison among MAC protocols

network traffic. Besides, it implements a p-persistent MAC scheme to reduce the probability of collisions during the transmission. In the Table 1 we summarize and compare those MAC protocols for VANETs.

\subsection{Network layer}

In the network layer, the routing protocol has to implement strategies that provide a reliable communication and do not disrupt the communication. Vehicular networks support different communication paradigms as shown in Figure 4. These can be categorized as follows:

- Unicast communication: the main goal is to perform data communication from a source node to a target node in the network via multi-hop wireless communication. The target node may be at either a precise known location or an approximate location within a specified range. Despite the unicast communication to be a useful mode in VANETs, multicast is more suitable for 


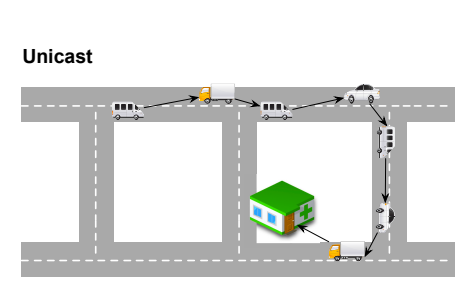

(a) Unicast

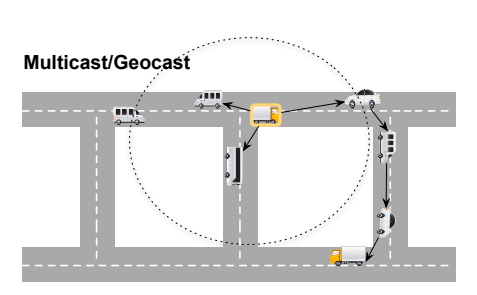

(b) Multicast/Geocast

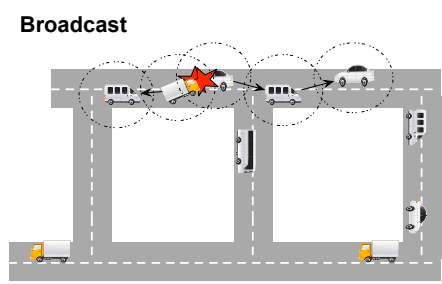

(c) Broadcast

Figure 4: Different communication scenarios in VANETs

applications that require dissemination of messages to different nodes in the network.

- Multicast/Geocast communication: the main goal is to perform data communication from a source node to a group of target nodes. Geocast is a specialized form of multicast addressing, in which a message is sent to a group of target nodes in a particular geographic position, usually relative to the source of the message.

- Broadcast communication: the main feature is to have a source node sending information to all neighbors' nodes at once. The neighbors' nodes that receive the broadcast message forward it through a new broadcast in order to deliver a message to the target nodes. Broadcast is also used at the discovery phase of some routing protocols in unicast communication paradigm in order to find an efficient route from the source vehicle to the target vehicle.

Two basic strategies for data forwarding commonly adopted in multi-hop wireless networks are topology-based and position-based routing [15, 25, 35, 52, 64]. Topologybased protocols use information about communication paths for packet transmission. In this case, every node maintains a routing table, which is the case of routing protocols for MANETs. Topology-based protocols can be further divided into proactive (tabledriven) and reactive (on-demand). Position-based protocols assume that the locations of the origin, its neighborhood and destination are known. Position-based protocols can also be further divided into delay tolerant, non-delay tolerant, and hybrid. Delay tolerant geographic routing protocols consider intermittent connectivity whereas non-delay tolerant protocols do not and are only useful in densely populated VANETs. Hybrid approaches take advantage of the partial network connectivity.

In principle, we could try to apply routing protocols developed for MANETs, such as AODV [55] and DSR [28], to VANETs since a vehicular network is a type of 
mobile ad hoc network with some distinct characteristics. However, those protocols do not present good performance in VANETs because of fast vehicle movement and relatively high speed of mobile nodes [37]. On the other side, due to continuous movements of vehicles, position-based routing seems to be more suitable for VANETs. With the increasing availability of navigation systems in vehicles, and improved position accuracy up to a few feet, this is a very reasonable assumption. Furthermore, position-based protocols do not exchange nor maintain link state information (as opposed to proactive and reactive topology-based protocols) and are more robust and promising to the highly dynamic environments like VANETs.

GPSR [30] is a well-known position-based routing protocol for MANETs based on a greedy forwarding mechanism. That protocol has a route discovery process that leads to significant delays in vehicular networks. In addition, with the rapid movement of vehicles, routing loops can be introduced while in the perimeter mode of GPSR. GPCR [41] and GPSRJ+ [34] are position-based protocols, based on GPSR, designed to improve the route discovery process in vehicular networks. Since they are position-based protocols, they do not have a global view of the network paths. D-Greedy/D-MinCost [63] and VADD [78] are also position-based protocols designed to consider errors in the route discovery process of GPSR. Basically, those protocols decide whether to forward packets or store them until a better forwarding node is found. They are also able to reduce packet delays and estimate path delays based on vehicle speed and number of intersections. Nevertheless, those protocols do not consider more relevant information like packet traffic congestion. A-STAR [60] and CAR [48] use traffic awareness for efficient packet delivery. Both protocols deal mainly with network connectivity issues and are not designed to address delay sensitive applications. PROMPT [24] is a cross-layer position-based delay-aware communication protocol that improves end-to-end delay using path information gathered by vehicles while propagating beacon messages.

The performance of routing protocols depends on different factors such as vehicular mobility model, data traffic, and road layouts. Data dissemination can significantly improve the data delivery ratio if, for instance, data buffers are located at road intersections [79]. There are also some protocols based on link and traffic metrics proposed for VANETs such as Multi-hop Routing protocol for Urban VANET (MURU) [47] and improved greedy traffic aware routing protocol (GyTAR) [26]. In contrast, we still need to further investigate the routing performance when physical, MAC, and network characteristics are all considered together [49].

When we consider the geocast routing, we can enumerate some routing protocols found in the literature. Two approaches to disseminate a message to a group are presented in $[3,8]$. In this scenario, one message is addressed to a specific set of 
vehicles according to an interest. The key idea of those routing protocols is to consider the position of the vehicles. Thus, according to their position, it is possible to determine if a message will be useful to a vehicle or not. For instance, the presence of obstacles or accident in a street or highway could require the notification of around vehicles. Thus, the first approach [8] sends a message to vehicles inside the zoneof-relevance. This zone considers an area where vehicles are, to define whether the message is relevant or not. The other approach, the protocol IVG [3], determines this area according to the driving direction, speed and the position of the vehicle.

Another principle in the geocast routing is caching [45] that, aiming to provide a good performance in delivery, combines the dissemination in a specific area. That approach is based on the main idea of adding a cache layer to hold packets and only to do the forward when a newly node is discovered. Thus, simulation results show that with this greedy routing the delivery success ratio can improve significantly.

Considering the task of reaching all vehicles, the broadcast communication is used by a group of protocols that rely on this strategy to establish and organize the routing structure. BROADCOMM [13] is a routing protocol designed for emergency environments. It uses a hierarchy scheme that defines two levels of nodes to broadcast the message. The goal is to improve the QoS features in a broadcast communication. Other strategy, the protocol UMB [33], is designed to address broadcast storm, hidden node, and reliability problems of multi-hop broadcast in urban areas [33]. This protocol achieves an efficient use of the channel and a high success rate in delivering a message.

Sun et al. [66] propose two strategies to perform a broadcast in a VANET. The first one (V-TRADE) uses a vector distance and GPS information to broadcast the message. The second one (HV-TRADE) uses the position history to guarantee the maximal reachability in the broadcast. Table 2 summarizes the main characteristics of the protocols mentioned above.

Maia et al. [43] propose HyDi, a broadcasting protocol for highway environments. HyDi combines broadcasting suppression strategies and store-carry-forward mechanisms to guarantee message delivery under varying road traffic densities. A limitation of such approach is its limited applicability under highway scenarios only. Maia et al. [44] extend their previous work and propose VoV, a broadcasting solution for urban environments with extreme road traffic conditions. Besides working under different road traffic densities, they propose a rate control mechanism that makes the protocols adaptable to the perceived radio channel condition. 


\begin{tabular}{|c|c|c|c|c|c|c|c|}
\hline \multirow{2}{*}{$\begin{array}{l}\text { Routing } \\
\text { Protocol }\end{array}$} & \multirow{2}{*}{$\begin{array}{l}\text { Comm. } \\
\text { Paradigm }\end{array}$} & \multicolumn{2}{|c|}{$\begin{array}{l}\text { Forwarding } \\
\text { Strategy }\end{array}$} & \multirow{2}{*}{$\begin{array}{l}\text { Architecture } \\
\text { V2V }\end{array}$} & Scenario & \multirow{2}{*}{$\begin{array}{l}\text { Application } \\
\text { CBR Traffic }\end{array}$} & \multirow{2}{*}{$\begin{array}{l}\text { Drawbacks } \\
\text { Greedy forwarding is of- } \\
\text { ten restricted to a city } \\
\text { scenario, because the di- } \\
\text { rect communication typ- } \\
\text { ically does not exist. }\end{array}$} \\
\hline & & $\begin{array}{l}\text { Greedy } \\
\text { warding }\end{array}$ & For- & & $\begin{array}{l}\text { Real City } \\
\text { Traces }\end{array}$ & & \\
\hline GPCR & Unicast & $\begin{array}{l}\text { Packet } \\
\text { warding }\end{array}$ & For- & $\mathrm{V} 2 \mathrm{~V}$ & $\begin{array}{l}\text { Real City } \\
\text { Traces }\end{array}$ & - & $\begin{array}{l}\text { It is not indicated to low } \\
\text { density scenarios. }\end{array}$ \\
\hline GPRSJ+ & Unicast & $\begin{array}{l}\text { Greedy } \\
\text { warding }\end{array}$ & For- & $\mathrm{V} 2 \mathrm{~V}$ & $\begin{array}{l}\text { Real City } \\
\text { Traces }\end{array}$ & CBR Traffic & $\begin{array}{l}\text { It needs more simula- } \\
\text { tions in more complex } \\
\text { and realistic trajectories. }\end{array}$ \\
\hline $\begin{array}{l}\text { D-Greedy/ } \\
\text { D-MinCost }\end{array}$ & Unicast & $\begin{array}{l}\text { Data } \mathrm{M} \\
\text { and } \mathrm{Mu} \\
\text { Forwardin }\end{array}$ & $\begin{array}{l}\text { uling } \\
\text { tihop } \\
\text { g }\end{array}$ & Hybrid & $\begin{array}{l}\text { Real City } \\
\text { Traces }\end{array}$ & - & $\begin{array}{l}\text { Protocols do not con- } \\
\text { sider local information in } \\
\text { the routing decision but } \\
\text { only the global informa- } \\
\text { tion. }\end{array}$ \\
\hline VADD & Unicast & $\begin{array}{l}\text { Packet } \\
\text { warding } \\
\text { Prediction }\end{array}$ & $\begin{array}{l}\text { For- } \\
\text { w/ }\end{array}$ & $\mathrm{V} 2 \mathrm{~V}$ & $\begin{array}{l}\text { Real City } \\
\text { Traces }\end{array}$ & CBR Traffic & $\begin{array}{l}\text { It is difficult to select an } \\
\text { outgoing edge freely. }\end{array}$ \\
\hline A-STAR & Unicast & $\begin{array}{l}\text { Packet } \\
\text { warding } \\
\text { Traffic Inf }\end{array}$ & $\begin{array}{l}\text { For- } \\
\text { w/ }\end{array}$ & $\mathrm{V} 2 \mathrm{~V}$ & $\begin{array}{l}\text { Grid City } \\
\text { Traces }\end{array}$ & CBR Traffic & $\begin{array}{l}\text { More appropriate for a } \\
\text { city environment. }\end{array}$ \\
\hline CAR & Unicast & $\begin{array}{l}\text { Packet } \\
\text { warding }\end{array}$ & For- & $\mathrm{V} 2 \mathrm{~V}$ & $\begin{array}{l}\text { Real City } \\
\text { Traces }\end{array}$ & CBR Traffic & $\begin{array}{l}\text { The model depends on } \\
\text { historical information } \\
\text { about the traffic density } \\
\text { and average velocity. }\end{array}$ \\
\hline PROMPT & Unicast & $\begin{array}{l}\text { Packet } \\
\text { warding } \\
\text { Position } \mathrm{E}\end{array}$ & $\begin{array}{l}\text { For- } \\
\text { w/ } \\
\text { ased }\end{array}$ & $\mathrm{V} 2 \mathrm{I}$ & $\begin{array}{l}\text { Grid City } \\
\text { Traces }\end{array}$ & $\begin{array}{l}\text { Variable } \\
\text { Traffic }\end{array}$ & $\begin{array}{l}\text { A simulation w/ realistic } \\
\text { model traffic to improve } \\
\text { the performance evalua- } \\
\text { tion of the protocol. }\end{array}$ \\
\hline MURU & Unicast & $\begin{array}{l}\text { Expected } \\
\text { connectiol } \\
\text { Heuristic }\end{array}$ & Dis- & $\mathrm{V} 2 \mathrm{~V}$ & $\begin{array}{l}\text { Grid City } \\
\text { Traces }\end{array}$ & CBR Traffic & $\begin{array}{l}\text { Overhead in the update } \\
\text { of EDD metric that is } \\
\text { the basis for the routing. }\end{array}$ \\
\hline GyTAR & Unicast & $\begin{array}{l}\text { Packet } \\
\text { warding } \\
\text { Street A } \\
\text { ness }\end{array}$ & $\begin{array}{l}\text { For- } \\
\text { w/ } \\
\text { ware- }\end{array}$ & $\mathrm{V} 2 \mathrm{~V}$ & $\begin{array}{l}\text { Real City } \\
\text { Traces }\end{array}$ & CBR Traffic & $\begin{array}{l}\text { Greedy approach de- } \\
\text { signed to city environ- } \\
\text { ments. }\end{array}$ \\
\hline $\begin{array}{l}\text { Direct Mes- } \\
\text { sage }\end{array}$ & Geocast & $\begin{array}{l}\text { Packet } \\
\text { warding }\end{array}$ & For- & $\mathrm{V} 2 \mathrm{~V}$ & $\begin{array}{l}\text { Road } \\
\text { Traces w/ } \\
\text { Accident }\end{array}$ & - & $\begin{array}{l}\text { Simple protocol that } \\
\text { uses only a maximal- } \\
\text { hop-number threshold } \\
\text { limit in a forwarding } \\
\text { decision. }\end{array}$ \\
\hline IVG & Geocast & $\begin{array}{l}\text { Packet } \\
\text { warding }\end{array}$ & For- & $\mathrm{V} 2 \mathrm{~V}$ & $\begin{array}{l}\text { Urban and } \\
\text { Rural Road } \\
\text { Traces }\end{array}$ & - & $\begin{array}{l}\text { Simple solution that de- } \\
\text { pends on a GPS equip- } \\
\text { ment. }\end{array}$ \\
\hline $\begin{array}{l}\text { Caching } \\
\text { Geocast }\end{array}$ & Geocast & $\begin{array}{l}\text { Packet } \\
\text { warding } \\
\text { caching }\end{array}$ & $\begin{array}{l}\text { For- } \\
\mathrm{w} /\end{array}$ & $\mathrm{V} 2 \mathrm{~V}$ & $\begin{array}{l}\text { Random } \\
\text { Traces }\end{array}$ & - & $\begin{array}{l}\text { In some scenarios, this } \\
\text { approach can be affected } \\
\text { by the network partition. }\end{array}$ \\
\hline BROADCOMM & Broadcast & $\begin{array}{l}\text { Packet } \\
\text { warding } \\
\text { Virtual C }\end{array}$ & $\begin{array}{l}\text { For- } \\
\text { w/ } \\
\text { lls }\end{array}$ & $\mathrm{V} 2 \mathrm{~V}$ & $\begin{array}{l}\text { Fixed } \\
\text { Traces }\end{array}$ & $\begin{array}{l}\text { Simple } \\
\text { Broadcast }\end{array}$ & $\begin{array}{l}\text { Naive performance eval- } \\
\text { uation. }\end{array}$ \\
\hline UMB & Broadcast & $\begin{array}{l}\text { Packet } \\
\text { warding }\end{array}$ & For- & Hybrid & $\begin{array}{l}\text { Urban } \\
\text { Traces }\end{array}$ & CBR Traffic & $\begin{array}{l}\text { Solution has a best per- } \\
\text { formance only in a dense } \\
\text { scenario. }\end{array}$ \\
\hline $\begin{array}{l}\text { V-TRADE/ } \\
\text { HV-TRADE }\end{array}$ & Broadcast & $\begin{array}{l}\text { Packet } \\
\text { warding } \\
\text { Vector } \\
\text { tance }\end{array}$ & $\begin{array}{l}\text { For- } \\
\text { w/ } \\
\text { Dis- }\end{array}$ & $\mathrm{V} 2 \mathrm{~V}$ & $\begin{array}{l}\text { Urban } \\
\text { and Rural } \\
\text { Traces }\end{array}$ & CBR Traffic & $\begin{array}{l}\text { The selection of forward- } \\
\text { ing nodes in every hop } \\
\text { causes an overhead. }\end{array}$ \\
\hline HyDi & Broadcast & Distance-1 & ased & $\mathrm{V}^{\mathrm{V}} 14$ & $\begin{array}{l}\text { Highway } \\
\text { Traces }\end{array}$ & - & $\begin{array}{l}\text { Only works under high- } \\
\text { way environments. }\end{array}$ \\
\hline VoV & Broadcast & $\begin{array}{l}\text { Geograph } \\
\text { and Dis } \\
\text { based }\end{array}$ & c & $\mathrm{V} 2 \mathrm{~V}$ & $\begin{array}{l}\text { Urban an } \\
\text { Random } \\
\text { Traces }\end{array}$ & $\begin{array}{l}\text { Video Dis- } \\
\text { semination }\end{array}$ & $\begin{array}{l}\text { Focuses on video dissem- } \\
\text { ination. }\end{array}$ \\
\hline
\end{tabular}

Table 2: Comparisons of Routing Protocols in VANETs 


\subsection{Transport and Applications layers}

As mentioned above, vehicular networks are characterized by intermittent connectivity and rapid topology changes. In contrast with other ad hoc networks, VANETs present more predictable mobility patterns. In these scenarios, vehicles connecting to an access point at higher speed have few seconds to download information in an environment with high losses that decrease the performance of both TCP and UDP protocols [53].

In VANETs, many unicast applications require a similar service as provided by TCP, i.e., a reliable and in-order data delivery. Unfortunately, TCP presents a poor performance in wireless networks that have a high degree of mobility and frequent topology changes [16]. Vehicular Transport Protocol (VTP) [59] is a transport protocol for unicast applications in VANETs that probes the network and uses statistical data to improve the performance when a connection is disrupted. Its design is based on the path characteristics that are relevant for a transport protocol for vehicular networks. Mobile Control Transport Protocol (MCTP) [5] is based on similar principles of the Ad Hoc TCP protocol [39]. Its main goal is to provide end-to-end QoS between a vehicle and an Internet host via a roadside infrastructure.

These transport protocols for VANETs are designed for applications that require unicast routing. However, many envisioned VANET applications require multicast communication, which requires new approaches not based on traditional transport protocols. The design of a reliable transport protocol for multicasting communication is a challenging design problem, since multicast protocols are usually stateless.

In the application layer, protocols should minimize the end-to-end communication delay, which is important when providing emergency information and in delay sensitive applications. In the former case, depending on the location that generated an emergency event and the location and velocity of the vehicle interested in receiving it, the application protocol may have to comply with real-time deadlines to guarantee that the vehicle's driver will be notified on time about this event. In the latter case, vehicular networks should have small end-to-end delay for making infotainment applications involving real-time multimedia available to users.

Application protocols may also be designed to develop marketing tools for business. For instance, restaurants, hotels, parks and gas stations can broadcast their information in VANETs and interested drivers or passengers can send a query to receive more information. Application protocols may also be used in business transactions. Again, such applications require delay-efficient and reliable networks.

Vehicular Information Transfer Protocol (VITP) [23] is an application-layer communication protocol designed to support the establishment of a distributed, ad hoc service infrastructure in VANETs. It is based on a location-aware stateless (similar 
to HTTP) transport protocol for V2I communication.

\section{VANET Applications}

Efficiency and safety are two important requirements that can be used to classify VANET applications based on their primary purpose. However, efficiency and safety are not completely separated from each other. On the contrary, those and other aspects should be considered together in the design of VANET applications. For instance, an engine failure or an accident involving two or more vehicles can lead to a traffic jam. A message reporting this event conveys a safety warning for nearby drivers who use it to increase their awareness. The same message may trigger the computation of an alternative route for a vehicle that planned to pass through the accident location, but it is not close to that point yet. In this case, the goal is to increase the transport efficiency for individual vehicles. Furthermore, depending on different factors such as the importance of the accident location, the transport system may compute and suggest alternative routes to a large set of vehicles considering a broader view of the traffic demands in order to diminish the impact of this event to regions not close to the accident. In this case, the goal is to increase the overall transport efficiency. Note that in both cases, an early event notification can help a driver or a passenger to decide to take a different route, use a different means of transport or even stay at the current location in case of a serious traffic problem. In this case, an additional goal is to provide a person with useful information in the planning of an activity related to the transport system.

VANET applications will monitor different types of data such as the vehicle conditions, surrounding roads, approaching vehicles, surface of the road and weather conditions to make the infrastructure more secure and more efficient. Once this data is available, vehicles will communicate via wireless communication networks among the other vehicles exchanging the relevant information for different purposes. According to Table 3, in the following we briefly discuss some of the existing and future applications for VANETs.

Safety Applications: The ultimate goal of safety applications in VANETs is to avoid and decrease the number of road accidents. This is an application category sensitive to the delay. Thus, in order to reduce the delay, in this category applications use vehicle-to-vehicle communication. Other requirement is the reliability, all vehicles close to the hazard have to alert about it. In case a collision occurs, there are two issues to deal with: the approaching vehicles and the accident location itself. Simple applications like sending emergency notifications to a call center that 
transfers the notification to emergency responders already exist, such as the GM's OnStar system [18]. Whenever an accident happens, an event (e.g., the release of an airbag) triggers a notification system to send emergency messages to nearby emergency responders. These notifications may carry the position provided by a GPS-enabled device. For future applications, depending on the distance to the accident that occurred further along the road, this application must warn the driver or even automatically break the vehicle (e.g. emergency breaking) when the distance decreases under a certain limit. It is also highly desirable to obtain emergency video streaming to help emergency responders (paramedics, fire fighters, and other rescue personnel). They could know before arriving on the scene the geographic location of the vehicle and traffic conditions at the site in order to respond more strategically to the incident. This video information can be obtained from vehicles equipped with video cameras, and with capabilities to store and forward images. The application could also monitor the post-collision scenario, taking appropriate actions and executing them promptly. Once an accident has occurred, the application should manage vehicle flows and identify alternative routes to either individual or a large set of vehicles, according to the accident location, time of the day and other factors. Of course, a safety application should be designed to act proactively providing drivers with early warnings and prevent an accident from happening in the first place.

Efficiency Applications: This is a category where the applications are aware of the vehicle location aiming to improve their mobility within the public roads. In this category, most of the applications require a high availability, because the drivers need of the provided information to make decisions during the trip, becoming the voyage more secure. In general, the communication pattern occurs among the vehicles and from vehicles to road side units. We can classify these applications in two ways: applications to control the crossroads and intersections, and applications to reduce and avoid traffic jams.

- Crossroads and intersections: Traffic control and management is an important research area that can benefit VANETs. For instance, vehicles passing near and through intersections should drive carefully since two or more traffic flows converge, and the possibility of collision increases. In this scenario, virtual traffic lights could control and manage the traffic flow at intersections. Another safety application is to warn the driver of an impending collision, who can take proper actions to prevent it. In both applications, i.e., virtual traffic lights and safety, there are stringent requirements to be attended, mainly related to real-time constraints and distributed processing. 
- Road congestion management: A road congestion application can provide drivers with the best routes to their destinations and also determine the best time schedules for traffic lights along the overall routes. The goal is to decrease congestion on the involved roads and maintain a smooth traffic flow. This can potentially increase the road capacity and prevent traffic jams.

Comfort Applications: In this category, drivers can receive information from vehicular services that may help the driver during the trip making it more comfortable and enjoyable. Normally, the typical application requirements are reliability and availability providing the information in the right moment that the driver needs. Such application type comprises: weather information, gas station or restaurant location, city leisure information, tourist information, information on the available parking lot at a parking place, international service handover, road charging, route navigation (e.g., estimated journey time, recommended information based on the user's context, automatic road map update, civilian surveillance) and advertisements or announcements of location-based sales information. In many cases, the communication will happen between vehicles and road side units, with no demand for a large bandwidth.

Interactive Entertainment: Aiming to distribute and to deliver entertainmentrelated information to drivers and passengers, this application category has as main features the connectivity and the availability. Thus, communication patterns can happen directly among vehicles or between vehicles and road sides. Ideally, the information should be tailored to the users' context. The challenge here is how to keep this context information up-to-date, considering the dynamics and mobility of vehicles and people in a VANET. After all, the synchronization among vehicles and central servers becomes a great challenge in this context. Examples of applications in this category are: Internet access, distributed games, microblogs, chats, music downloads, web browsing, file sharing, home control, etc. In future generation applications, passengers will have the opportunity to interact with passengers in nearby vehicles or with people anywhere in the world through instant messaging services, games, and even videoconference.

Urban Sensing: A vehicular network can be seen as a network paradigm for urban monitoring and for sharing data of common interest. This is particularly true in urban areas, where we can expect to have a high concentration of vehicles equipped with onboard sensors. Vehicular networks can be used for effective monitoring of environmental conditions and social activities in urban areas, playing an important 
role in urban sensing $[12,71]$. Urban sensing applications can be further potentialized when smartphone capabilities taken onboard can be used complementarily with VANET sensors [36, 40]. In this context, the design of a Vehicular Sensor Network (VSN) introduces novel and challenging issues, which are considerably different from traditional wireless sensor networks, thus requiring innovative solutions. This is a promising research area since vehicles are not affected by energy constraints and other restrictions. Vehicles can be equipped with powerful processing units, different wireless communication devices, navigation systems, and a plethora of sensing devices such as chemical detectors, vibration/acoustic sensors, and still/video cameras. The combination of vehicular and sensor networks presents a tremendous opportunity for different large-scale applications in VANETs ranging from traffic routing and relief to environmental monitoring, distributed surveillance and mobile social networks.

Table 3 summarizes the main characteristics of the discussed categories, where applications are classified according to their features, communication requirements, existing protocol solutions, and pull-based vs. push-based mechanisms.

\section{Challenges and Future Perspectives}

Given the challenges and characteristics of VANETs, some future perspectives should be considered to design new efficient communication approaches, as follows:

Highly heterogeneous vehicular networks: many non-interoperable wireless networking technologies have emerged with the rapid development and availability of mobile computing systems and environments. As a consequence, the provision of seamless connectivity across different wireless networking technologies under a time-varying network topology is very complex in terms of node addressing, quality of service, routing, security and billing. Thus, it is expected that the next generation of intelligent transportation systems reflect a more holistic approach to network solutions. This would require support to the coexistence of multiple different co-located wireless networks to provide ubiquitous and universal access to broadband services [17].

Data management and storage: As outlined above, we can expect to have large scale vehicular networks with millions of vehicles, which will generate huge

amounts of distributed data that must be stored in some fashion and distributed across the VANETs. Due to this feature, as pointed out in [38, 74], the massive scale, both in the size of network and amount of produced data, as well as the inherent dynamic properties of VANETs, pose new and unique challenges to data management in this setting. 
Localization systems: Critical safety applications in VANETs require more reliable and high accurate localization systems. A natural solution of a localization system for VANETs is to embed a navigation device in each vehicle. But satellitebased positioning systems (e.g., GPS, Galileo) present some undesired problems such as not always being available (e.g., reception problems in tunnels caused by lack of signals or on bridges due to vehicle position imprecision: over or under the bridge). Furthermore, satellite-based positioning systems are vulnerable to several types of attacks such as spoofing and blocking. In addition, it has a localization error of 10 to $30 \mathrm{~m}$, which does not satisfy the requirements of critical applications for VANETs and implies the need for other localization techniques. A number of localization techniques has been proposed for computing the position of mobile nodes [7], namely Map Matching, Dead Reckoning, Cellular Localization, Image/Video Processing, Localization Services, Differential GPS technique, and Relative Distributed Ad Hoc Localization. All these techniques have advantages and disadvantages, but no single technique can satisfy all the requirements of critical applications at the same time, such as availability anywhere and anytime, with high accuracy and reliable position computation. A reliable and ubiquitous localization system to be used by vehicles in a VANET for critical safety and emergency applications will likely be provided by a combination of different techniques and data fusion. However, unique characteristics of VANETs such as: mobility constraints defined by public roads, driver behaviors, and high speed of vehicles cause a lot of changes in the network topology, which lead to the dissemination of an outdated position information. Moreover, some solutions to increase the beacon frequency generate an unnecessary overhead, hindering the transmission of other data. Thus, the study of models to predict the position of vehicles during the time becomes a good alternative in the localization systems.

Security and privacy: Several network security issues resemble those of traditional wireless networks. However, security challenges in VANETs are intrinsic and unique due to the size of the network, frequent topology changes, high mobility, and the different classes of applications and services, with conflicting requirements that will be offered to such networks. Besides those challenges, there is a trade-off between authentication and non-repudiation versus privacy [65]. Another major issue is to prevent attackers from interfering with both the integrity of the exchanged messages and the availability of the system. Some characteristics of VANETs pose challenges to meet security requirements, which demand novel protocol solutions with some of the following characteristics $[56,65,76]$ : low overhead due to time sensitivity, minimum hops communication among nodes, pre-stored information about the 
participating routing nodes and optimized data dissemination solutions. Despite the valuable existing results addressing the problem of security in VANETs, new secure communication protocols must be investigated taking into consideration the unique characteristics of heterogeneous vehicular networks.

Disruptive tolerant communications: Current problems, such as higher delay and lower reliability delivery, are more constant in sparse networks. To increase the delivery reliability, some solutions make use of the carry-and-forward technique, which further increases the information delivery time. Those problems may be solved/minimized exploring new data communication approaches for Heterogeneous Vehicular Networks. As another alternative, the driver's behavior can be considered to improve the carry-and-forward method and reduce the information delivery time.

Geographical addressing: The physical position of a vehicle or its geographic region is necessary for many applications to perform data communication, which requires a geographical address. Three geographical addressing families are presented in $[21,29,50]$ : application layer solutions, GPS-multicast solution and Unicast IP routing extended to deal with GPS addresses. Thus, given the vehicles' mobility pattern and drivers' behavior, tracking and managing geographical addresses to predict the future position of a vehicle is a problem extremely challenging.

Tracking a target: Communication is a fundamental aspect in any network and, in VANETs, depends on the physical location of vehicles. Therefore, tracking a target is a fundamental functionality in VANETs for communication protocols and also for applications and services that can benefit from this type of information [67]. Tracking requires creating a mechanism to identify the path a node follows in the network and predict the next positions if necessary. As pointed out before, privacy issues have to be observed in the devised solutions.

Standardization of protocols: VANETs can be comprised of different types of vehicles such as trucks, cars, trams, buses, taxis motorbikes and bicycles. In this scenario, it is important that all of them are able to communicate among themselves using the same protocol. This can only be achieved in case there is an standardization effort involving industry, government and academia [29].

Cooperation with other networks: We can expect to have drivers and passengers in a VANET interacting with people, applications and services in other networks. This cooperation can be useful to provide a good service to the user, like informa- 
tion about traffic conditions, weather, and routes. This information can be obtained through interactions with sensor networks, Internet, and other services.

Variable network density: In urban scenarios, the VANET topology can have hundreds of vehicles in a relatively small region. In this case, it is necessary to design protocols for medium access control to avoid collision and transmission errors. However, in highway scenarios the topology is sparser and the connectivity is more intermittent. This scenario suggests the need of protocols aware of these disconnections. Also, vehicles that travel in both scenarios need to adapt their behavior to network density variations in order to provide a good data transfer.

Network fragmentation: Network fragmentation is a challenge for network designers since it causes some of the nodes to become unreachable. Network fragmentation may occur in scenarios of light traffic or rural areas. Also, it is expected that the initial deployment of VANET radios, in which only a small percentage of vehicles will be equipped with transceivers, will lead to frequent fragmentation of the network [20]. Traditional protocol solutions, such as those relying on topology information in a node, are not suitable for VANETs and new approaches are required.

\section{Conclusion}

Wireless vehicular networking is a key enabling technology for future intelligent transportation systems, smart vehicles, and smart infrastructure. The advent of vehicular networks comprised of vehicles equipped with the ability to establish wireless communications and self-organize into a collaborative mesh, opens a countless of applications that can make road travel safer (by avoiding collisions), more efficient (by decreasing travel time, avoiding traffic congestion, and increasing road capacity), and more pleasant to the users. In fact, VANETs are likely to become the most important realization of mobile ad hoc networks.

The distinct characteristics of VANETs lead to specific networking problems, demanding the design of fully distributed protocols. VANETs introduce additional challenges for protocol designers, besides those already present in mobile ad hoc networks. In particular, the mobility of vehicles results in a dynamic scenario with substantial rate of link changes and, consequently, very short lifetime for multihop paths. In this case, protocols that need to know the state of the system (even if only local) are inefficient due to the frequent network changes. In addition, VANET applications may require (or may benefit from) a different protocol stack.

There are many exciting research challenges in different areas yet to be solved that need to be incorporated into real deployment since innovation heavily depends 
on acceptance of technology. During the last decade, there were significant advances in VANET research and the associated technology, which have sparked a lot of interest in different research communities such as transportation, wireless communication, and networking. Several automotive companies, research institutions, and government organizations are currently involved in evaluating, proposing, creating, and engineering future VANET systems, which will come from opportunities and synergies of interconnected vehicles and infrastructures. A common and fundamental aspect in all aspects of vehicular networks is the different type of algorithms employed in VANETs.

This work brought discussions on the main characteristics of vehicular networks, architecture details, constraints of layers, protocols, applications and future perspectives. We hope the insight discussed here will help protocols' designers and applications engineers to improve the services provided in this type of network, and assist drivers in making secure trips.

\section{References}

[1] Saif Al-Sultan, Moath M. Al-Doori, Ali H. Al-Bayatti, and Hussien Zedan. A comprehensive survey on vehicular ad hoc network. Journal of Network and Computer Applications, 37(0):380 - 392, 2014.

[2] Mohammad S. Almalag, Michele C. Weigle, and Stephan Olariu. MAC Protocols for VANET, pages 599-618. John Wiley and Sons, Inc., 2013.

[3] A. Bachir and A. Benslimane. A multicast protocol in ad hoc networks intervehicle geocast. In Vehicular Technology Conference, 2003. VTC 2003-Spring. The 57th IEEE Semiannual, volume 4, pages 2456-2460, april 2003.

[4] S. Barghi, A. Benslimane, and C. Assi. A lifetime-based routing protocol for connecting vanets to the internet. In World of Wireless, Mobile and Multimedia Networks Workshops, 2009. WoWMoM 2009. IEEE International Symposium on a, pages 1-9, June 2009.

[5] Marc Bechler, Sven Jaap, and Lars Wolf. An optimized tcp for internet access of vehicular ad hoc networks. In 4th International IFIP-TC6 Networking Conference (NETWORKING'05), pages 869-880. Volume 3462 of Lecture Notes in Computer Science, Springer, 2005.

[6] Flaminio Borgonovo, Antonio Capone, Matteo Cesana, and Luigi Fratta. Adhoc mac: New mac architecture for ad hoc networks providing efficient and reliable 
point-to-point and broadcast services. Wireless Networks, 10(4):359-366, July 2004.

[7] Azzedine Boukerche, Horacio A. B. F. Oliveira, Eduardo F. Nakamura, and Antonio A. F. Loureiro. Vehicular ad hoc networks: A new challenge for localization-based systems. Comput. Commun., 31:2838-2849, July 2008.

[8] L. Briesemeister, L. Schafers, and G. Hommel. Disseminating messages among highly mobile hosts based on inter-vehicle communication. In Intelligent Vehicles Symposium, 2000. IV 2000. Proceedings of the IEEE, pages 522-527, 2000.

[9] Po-Yu Chen, Je-Wei Liu, and Wen-Tsuen Chen. A fuel-saving and pollutionreducing dynamic taxi-sharing protocol in vanets. In Vehicular Technology Conference Fall (VTC 2010-Fall), 2010 IEEE 72nd, pages 1-5, Sept 2010.

[10] J. Chennikara-Varghese, null Wai Chen, O. Altintas, and null Shengwei Cai. Survey of routing protocols for inter-vehicle communications. Mobile and Ubiquitous Systems, Annual International Conference on, 0:1-5, 2006.

[11] N.M. Chowdhury, L. Mackenzie, and C. Perkins. Requirement analysis for building practical accident warning systems based on vehicular ad-hoc networks. In Wireless On-demand Network Systems and Services (WONS), 2014 11th Annual Conference on, pages 81-88, April 2014.

[12] Dana Cuff, Mark Hansen, and Jerry Kang. Urban sensing: Out of the woods. Communications of the ACM, 51(3):24-33, March 2008.

[13] M. Durresi, A. Durresi, and L. Barolli. Emergency broadcast protocol for intervehicle communications. In Parallel and Distributed Systems, 2005. Proceedings. 11th International Conference on, volume 2, pages 402-406, july 2005.

[14] A. Festag. Cooperative intelligent transport systems standards in europe. Communications Magazine, IEEE, 52(12):166-172, December 2014. ISSN 0163-6804. doi: 10.1109/MCOM.2014.6979970.

[15] Antnio Fonseca and Teresa Vazo. Applicability of position-based routing for vanet in highways and urban environment. Journal of Network and Computer Applications, 36(3):961 - 973, 2013.

[16] Zhenghua Fu, Xiaoqiao Meng, and Songwu Lu. How bad tcp can perform in mobile ad hoc networks. In 7th International Symposium on Computers and Communications (ISCC'02), pages 298-303, 2002. 
[17] National Science Fundation, 2012. URL http://1.usa.gov/16kJQ3T.

[18] General Motors'. Onstar, 2010. URL http://www.onstar.com.

[19] S. Grafling, P. Mahonen, and J. Riihijarvi. Performance evaluation of ieee 1609 wave and ieee 802.11p for vehicular communications. In Ubiquitous and Future Networks (ICUFN), 2010 Second International Conference on, pages 344-348, June 2010.

[20] J. Guo and N. Balon. Vehicular ad hoc networks and dedicated short-range communication, 2006.

[21] Tomasz Imieliński and Julio C. Navas. Gps-based geographic addressing, routing, and resource discovery. Commun. ACM, 42:86-92, April 1999.

[22] European Telecommunications Standards Institute. Intelligent transport systems (its); radiocommunications equipment operating in the $5855 \mathrm{mhz}$ to $5925 \mathrm{mhz}$ frequency band. Technical Report ETSI EN 302571 V1.2.0, ETSI, France, May 2013.

[23] Marios D. Dikaiakosand Saif Iqbal and Tamer Nadeemand Liviu Iftode. Vitp: An information transfer protocol for vehicular computing. In Proceedings of the 2nd ACM International Workshop on Vehicular Ad Hoc Networks (VANET'05), pages 30-39, 2005.

[24] Boangoat Jarupan and Eylem Ekici. Prompt: A cross-layer position-based communication protocol for delay-aware vehicular access networks. Ad Hoc Networks, 8:489-505, 2010.

[25] M. Jerbi, S.-M. Senouci, T. Rasheed, and Y. Ghamri-Doudane. Towards efficient geographic routing in urban vehicular networks. IEEE Transactions on Vehicular Technology, 58(9):5048-5059, 2008.

[26] Moez Jerbi, Sidi-Mohammed Senouci, Rabah Meraihi, and Yacine GhamriDoudane. An improved vehicular ad hoc routing protocol for city environments. In Proceedings of the IEEE International Conference on Communications (ICC'07), pages 3972-3979, 2007.

[27] D. Jiang and L. Delgrossi. Ieee 802.11p: Towards an international standard for wireless access in vehicular environments. In Vehicular Technology Conference, 2008. VTC Spring 2008. IEEE, pages 2036-2040, May 2008. 
[28] D. Johnson, D. Maltz, and J. Broch. Dsr: Dynamic source routing protocol for multi-hop wireless ad hoc networks. Ad Hoc Networking, 1:139-172, 2001.

[29] G. Karagiannis, O. Altintas, E. Ekici, G. J. Heijenk, B. Jarupan, K. Lin, and T. Weil. Vehicular networking: A survey and tutorial on requirements, architectures, challenges, standards and solutions. IEEE Communications Surveys $\&$ Tutorials, 2011.

[30] B. Karp and H. Kung. Gpsr: Greedy perimeter stateless routing for wireless networks. In Proceedings of the 6th Annual International Conference on Mobile Computing and Networking (MobiCom'00), pages 243-254, 2000.

[31] J.B. Kenney. Dedicated short-range communications (dsrc) standards in the united states. Proceedings of the IEEE, 99(7):1162-1182, 2011.

[32] Young-Bae Ko, Vinaychandra Shankarkumar, and Nitin H. Vaidya. Medium access control protocols using directional antennas in ad hoc networks. In Proceedings of the 19th Annual Joint Conference of the IEEE Computer and Communications Societies (INFOCOM'00), pages 13-21, 2000.

[33] Gökhan Korkmaz, Eylem Ekici, Füsun Özgüner, and Ümit Özgüner. Urban multihop broadcast protocol for inter-vehicle communication systems. In Proceedings of the 1st ACM international workshop on Vehicular ad hoc networks, VANET '04, pages 76-85, New York, NY, USA, 2004. ACM.

[34] K. Lee, J. Haerri, U. Lee, and M. Gerla. Enhanced perimeter routing for geographic forwarding protocols in urban vehicular scenarios. In IEEE Globecom Workshops, pages 1-10, 2007.

[35] Kevin C. Lee, Uichin Lee, and Mario Gerla. Survey of routing protocols in vehicular ad hoc networks. In Mohamed Watfa, editor, Advances in Vehicular Ad-Hoc Networks: Developments and Challenges, chapter 8, pages 149-170. IGI Global, 2010.

[36] Uichin Lee and Mario Gerla. A survey of urban vehicular sensing platforms. Comput. Netw., 54(4):527-544, March 2010.

[37] F. Li and Y. Wang. Routing in vehicular ad hoc networks: A survey. IEEE Vehicular Technology Magazine, 2(2):12-22, 2007.

[38] Wolfgang Lindner and Samuel Madden. Data management issues in disconnected sensor networks. In GI Jahrestagung (2)'04, pages 349-354, 2004. 
[39] Jian Liu and Suresh Singh. Atcp: Tcp for mobile ad hoc networks. IEEE Journal on Selected Areas in Communications, 19(7):1300-1315, July 2001.

[40] Shou-Chih Lo, Jhih-Siao Gao, and Chih-Cheng Tseng. A water-wave broadcast scheme for emergency messages in vanet. Wireless Personal Communications, 71 (1):217-241, 2013.

[41] C. Lochert, M. Mauve, H. Fler, and H. Hartenstein. Geographic routing in city scenarios. ACM SIGMOBILE Mobile Computing and Communications Review, 9(1):69-72, 2005.

[42] Jun Luo and Jean-Pierre Hubaux. A survey of research in inter-vehicle communications. Embedded Security in Cars, pages 111-122, 2006.

[43] Guilherme Maia, Andre L.L. Aquino, Aline Viana, Azzedine Boukerche, and Antonio A.F. Loureiro. HyDi: A Hybrid Data Dissemination Protocol for Highway Scenarios in Vehicular Ad Hoc Networks. In ACM International Symposium on Design and Analysis of Intelligent Vehicular Networks and Applications (DIVANet '12), pages 115-122, 2012.

[44] Guilherme Maia, Cristiano Rezende, Leandro A. Villas, Azzedine Boukerche, Aline C. Viana, Andre L. Aquino, and Antonio A. Loureiro. Traffic aware video dissemination over vehicular ad hoc networks. In ACM International Conference on Modeling, Analysis and Simulation of Wireless and Mobile Systems (MSWiM '13), pages 419-426, 2013.

[45] C. Maihofer and R. Eberhardt. Geocast in vehicular environments: caching and transmission range control for improved efficiency. In Intelligent Vehicles Symposium, 2004 IEEE, pages 951-956, june 2004.

[46] Hamid Menouar, Fethi Filali, and Massimiliano Lenardi. A survey and qualitative analysis of mac protocols for vehicular ad hoc networks. IEEE Wireless Communications, 13(5):30-35, October 2006.

[47] Zhaomin Mo, Hao Zhu, Kia Makki, and Niki Pissinou. Muru: A multi-hop routing protocol for urban vehicular ad hoc networks. In 3rd Annual International Conference on Mobile and Ubiquitous Systems (MobiQuitous'06), pages 1-8, 2006.

[48] V. Naumov and T. Gross. Connectivity-aware routing (car) in vehicular ad-hoc networks. In 26th IEEE International Conference on Computer Communications (INFOCOM'O7), pages 1919-1927, 2007. 
[49] Valery Naumov, Rainer Baumann, and Thomas Gross. An evaluation of intervehicle ad hoc networks based on realistic vehicular traces. In Proceedings of the 7th ACM International Symposium on Mobile Ad Hoc Networking and Computing (MobiHoc'06), pages 108-119, 2006.

[50] Julio C. Navas and Tomasz Imielinski. Geocast - geographic addressing and routing. In Proceedings of the 3rd annual ACM/IEEE international conference on Mobile computing and networking, MobiCom '97, pages 66-76, New York, NY, USA, 1997. ACM.

[51] DIVA Developing Next Generation Intelligent Vehicular Networks and Applications. URL http://nsercdiva.com/.

[52] P.S. Nithya Darisini and N.S. Kumari. A survey of routing protocols for vanet in urban scenarios. In Pattern Recognition, Informatics and Mobile Engineering (PRIME), 2013 International Conference on, pages 464-467, Feb 2013.

[53] J. Ott and D. Kutscher. Drive-thru internet: Ieee 802.11b for "automobile" users. In INFOCOM 2004. Twenty-third AnnualJoint Conference of the IEEE Computer and Communications Societies, volume 1, pages 4 vol. (xxxv+2866), march 2004.

[54] Panos Papadimitratos, Arnaud De La Fortelle, Knut Evenssen, Roberto Brignolo, and Stefano Cosenza. Vehicular communication systems: Enabling technologies, applications, and future outlook on intelligent transportation. Comm. Mag., 47 (11):84-95, November 2009.

[55] C. Perkins and E. Royer. Ad-hoc on-demand distance vector routing. In Second IEEE Workshop on Mobile Computing Systems and Applications (WMCSA'99), pages 90-100, 1999.

[56] M. Raya, P. Papadimitratos, and J. Hubaux. Securing vehicular communications. IEEE Wireless Communications, Special Issue on Inter-Vehicular Communications, pages 8-15, 2006.

[57] M.A. Razzaque, AhmadSalehi S., and SeyedM. Cheraghi. Security and privacy in vehicular ad-hoc networks: Survey and the road ahead. In M.A. Razzaque, AhmadSalehi S., and SeyedM. Cheraghi, editors, Wireless Networks and Security, Signals and Communication Technology, pages 107-132. Springer Berlin Heidelberg, 2013. 
[58] Beerthi Sahadev, Kapil S. Zade, and Sakeeb H. Sheikh. Article: Survey on realistic simulation for comparison of network routing protocol in vanet. IJAIS Proceedings on 2nd National Conference on Innovative Paradigms in Engineering and Technology (NCIPET 2013), NCIPET(2):26-29, November 2013. Published by Foundation of Computer Science, New York, USA.

[59] Ralf Schmitz, Alain Leiggener, Andreas Festag, Lars Eggert, and Wolfgang Effelsberg. Analysis of path characteristics and transport protocol design in vehicular ad hoc networks. In Proceedings of the IEEE 63rd Vehicular Technology Conference (VTC'06), pages 528-532, 2006.

[60] Boon-Chong Seet, Genping Liu, Bu-Sung Lee, Chuan-Heng Foh, Kai-Juan Wong, and Keok-Kee Lee. A-star: A mobile ad hoc routing strategy for metropolis vehicular communications. In 3rd International IFIP-TC6 Networking Conference (NETWORKING'04), pages 989-999. Volume 3042 of Lecture Notes in Computer Science, Springer, 2004.

[61] Caixing Shao, Supeng Leng, Yan Zhang, and Huirong Fu. A multi-priority supported medium access control in vehicular ad hoc networks. Computer Communications, 39(0):11 - 21, 2014. Research advances and standardization activities in WLANs Research advances and standardization activities in WLANs.

[62] Mihail L. Sichitiu and Maria Kihl. Inter-vehicle communication systems: A survey. IEEE Communications Surveys and Tutorials, 10:88-105, 2008.

[63] A. Skordylis and N. Trigoni. Delay-bounded routing in vehicular ad-hoc networks. In Proceedings of the 9th ACM International Symposium on Mobile Ad Hoc Networking and Computing (MobiHoc'08), pages 341-350, 2008.

[64] M. Slavik and I. Mahgoub. Spatial distribution and channel quality adaptive protocol for multihop wireless broadcast routing in vanet. Mobile Computing, IEEE Transactions on, 12(4):722-734, April 2013.

[65] Antonios Stampoulis and Zheng Chai. A survey of security in vehicular networks. http://zoo. cs. yale. edu/ ams257/projects/wireless-survey. pdf (accessed: Nov 28, 2011), 2007.

[66] Min-Te Sun, Wu-Chi Feng, Ten-Hwang Lai, K. Yamada, H. Okada, and K. Fujimura. Gps-based message broadcasting for inter-vehicle communication. In Parallel Processing, 2000. Proceedings. 2000 International Conference on, pages $279-286,2000$. 
[67] G. Thomaidis, K. Vassilis, P. Lytrivis, M. Tsogas, G. Karaseitanidis, and A. Amditis. Target tracking and fusion in vehicular networks. In Intelligent Vehicles Symposium (IV), 2011 IEEE, pages 1080 -1085, june 2011.

[68] Yasser Toor, Paul Mühlethaler, Anis Laouiti, and Arnaud de La Fortelle. Vehicle ad hoc networks: Applications and related technical issues. IEEE Communications Surveys and Tutorials, 10(1-4):74-88, 2008.

[69] Anna Izabel J. Tostes, Fátima de L. P. Duarte-Figueiredo, Renato Assunção, Juliana Salles, and Antonio A. F. Loureiro. From data to knowledge: City-wide traffic flows analysis and prediction using bing maps. In Proceedings of the $2 \mathrm{Nd}$ ACM SIGKDD International Workshop on Urban Computing, UrbComp '13, pages 12:1-12:8, New York, NY, USA, 2013. ACM.

[70] S. Tsugawa. Inter-vehicle communications and their applications to intelligent vehicles: an overview. Intelligent Vehicle Symposium, 2002. IEEE, 2, 2002.

[71] Eugenio Magistretti Uichin Lee, Mario Gerla, Paolo Bellavista, and Antonio Corradi. Dissemination and harvesting of urban data using vehicular sensing platforms. IEEE Transactions on Vehicular Technology, 58(2):882-901, February 2009.

[72] Md Whaiduzzaman, Mehdi Sookhak, Abdullah Gani, and Rajkumar Buyya. A survey on vehicular cloud computing. Journal of Network and Computer Applications, 40(0):325 - 344, 2014.

[73] T. L. Willke, P. Tientrakool, and N. F. Maxemchuk. A survey of inter-vehicle communication protocols and their applications. Communications Surveys $\&$ Tutorials, 11(2):3-20, June 2009.

[74] Ouri Wolfson, Bo Xu, and Hyung Ju Cho. Multimedia traffic information in vehicular networks. In Proceedings of the 17th ACM SIGSPATIAL International Conference on Advances in Geographic Information Systems, GIS '09, pages 480-483, New York, NY, USA, 2009. ACM.

[75] Qiben Yan, Ming Li, Zhenyu Yang, Wenjing Lou, and Hongqiang Zhai. Throughput analysis of cooperative mobile content distribution in vehicular network using symbol level network coding. IEEE Journal on Selected Areas in Communications, 30(2):484-492, 2012. 
[76] S. Zeadally, Y. Chen R. Hunt, A. Irwin, and A. Hassan. Vehicular ad hoc networks (vanets): Status, results, and challenges. to appear in Telecommunication Systems, $51(2-3), 2012$.

[77] Jin Zhang, Qian Zhang, and Weijia Jia. Vc-mac: A cooperative mac protocol in vehicular networks. Vehicular Technology, IEEE Transactions on, 58(3): 1561-1571, March 2009.

[78] J. Zhao and G. Cao. Vadd: Vehicle-assisted data delivery in vehicular ad hoc networks. IEEE Transactions on Vehicular Technology, 57(3):1910-1922, 2008.

[79] Jing Zhao, Yang Zhang, and Guohong Cao. Data pouring and buffering on the road: A new data dissemination paradigm for vehicular ad hoc networks. IEEE Transactions on Vehicular Technology, 56(6):3266-3277, November 2007. 


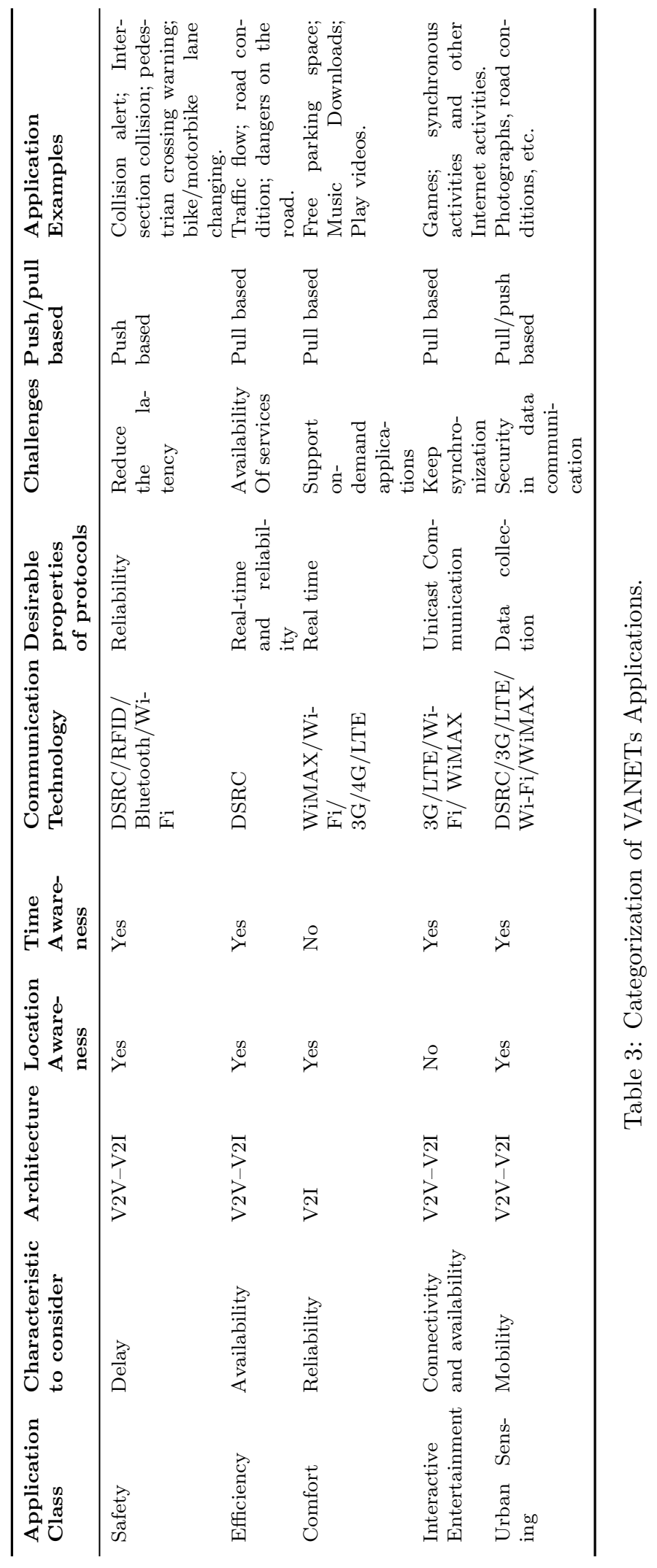

